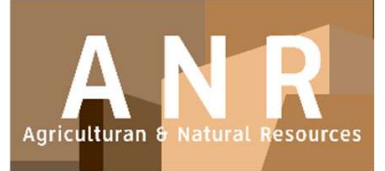

PAPER - OPEN ACCESS

Pemetaan Kesehatan Pohon di Hutan Konservasi (Studi Kasus Tahura Wan Abdul Rachman, Desa Cilimus Kecamatan Teluk Pandan Kabupaten Pesawaran Provinsi Lampung)

$\begin{array}{ll}\text { Author } & : \text { Rahmat Safe'I dkk., } \\ \text { DOI } & : 10.32734 \text { anr.v3i1.839 } \\ \text { Electronic ISSN } & : 2654-7023 \\ \text { Print ISSN } & : 2654-7015\end{array}$

Volume 3 Issue 1-2020 TALENTA Conference Series: Agriculturan \& Natural Resource (ANR)

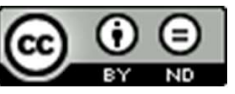

This work is licensed under a Creative Commons Attribution-NoDerivatives 4.0 International License.

Published under licence by TALENTA Publisher, Universitas Sumatera Utara

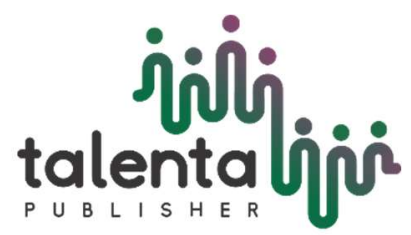




\title{
Pemetaan Kesehatan Pohon di Hutan Konservasi (Studi Kasus Tahura Wan Abdul Rachman, Desa Cilimus Kecamatan Teluk Pandan Kabupaten Pesawaran Provinsi Lampung)
}

\author{
Rahmat Safe' ${ }^{\mathrm{a}, *}$, Arief Darmawan ${ }^{\mathrm{a}}$, dan Hari Kaskoyo ${ }^{\mathrm{a}}$ \\ ${ }^{a}$ Jurusan Kehutanan, Fakultas Pertanian, Universitas Lampung Jln. Prof. Dr. Soemantri Brodjonegoro No. 1 Bandar Lampung 35145 Tel./Fax. \\ $+62-721-704946$ \\ rahmat.safei@fp.unila.ac.id
}

\begin{abstract}
Abstrak
Pohon merupakan penyusun utama sebuah hutan. Hutan konservasi yang sehat harus tersusun dari pepohonan yang sehat pula. Tahura Wan Abdul Rahman termasuk hutan konservasi dalam bentuk kawasan pelestarian alam. Salah satu cara untuk mengetahui hutan konservasi yang sehat, yaitu dengan melakukan pemetaan kesehatan pohon. Penelitian ini bertujuan untuk mengetahui sebaran kondisi kesehatan pohon di hutan konservasi. Penelitian ini dilaksanakan pada hutan konservasi di Desa Cilimus, Kecamatan Teluk Pandan, Kabupaten Pesawaran, Provinsi Lampung. Penelitian ini menggunakan metode penilaian kerusakan pohon berdasarkan teknik Forest Health Monitoring (FHM). Plot ukur sampel berdasarkan desain klaster-plot FHM sebanyak dua klaster-plot. Hasil penelitian menunjukkan bahwa terdapat 47 pohon yang dinilai kesehatan pohonnya; dengan 4 pohon (9\%) pada kategori baik, 16 pohon (34\%) pada ketegori sedang, dan 27 pohon (57\%) pada kategori jelek. Kerusakan pohon yang paling banyak ditemukan, yaitu pada lokasi cabang (kode 7$)$ sebanyak $16(25,40 \%)$ dengan tipe kerusakan daun, pucuk atau tunas rusak (kode 24) sebanyak 20 (31,75\%). Dengan demikian, sebaran kesehatan pohon yang rusak pada hutan konservasi tersebar secara menyeluruh dengan tingkat kondisi kesehatan pohon yang jelek.
\end{abstract}

Kata kunci: Forest Health Monitoring; hutan konservasi; kesehatan pohon

\section{Pendahuluan}

Perkembangan ilmu tentang kesehatan hutan di Indonesia menjadikan ilmu kesehatan hutan dapat diaplikasikan pada suatu manajemen pengelolaan hutan tertentu. Namun rendahnya kesadaran akan pentingnya kesehatan hutan dalam mencapai pengelolaan hutan yang lestari menjadi sebuah permasalahan yang belum mendapat perhatian serius, salah satunya pada hutan konservasi [7]. Padahal kesehatan hutan merupakan suatu cara untuk dapat mengetahui kondisi kestabilan ekosistem pada suatu hutan agar hutan tersebut tetap dapat mengemban fungsi yang telah ditetapkan secara optimal. Salah satu indikator keberhasilan pengelolaan hutan konservasi adalah indikator kesehatan hutan melalui penilaian kerusakan pohon. Penilaian kerusakan pohon tersebut dilakukan untuk mengetahui kesehatan pohon yang ada pada suatu hutan sehingga diperoleh suatu gambaran kondisi kesehatan hutan secara komperehensif. Saat ini pengelolaan kesehatan hutan secara modern berupaya untuk mengendalikan kerusakan agar tetap di bawah ambang ekonomi yang masih dapat diterima. Intensitas pengendalian diperlukan jika kerusakan sudah di atas ambang ekonomi dan jumlah biaya yang dikeluarkan tergantung dari tujuan pengelolaan dan besarnya kerugian yang terjadi [2].

Kesehatan pohon dapat dilakukan dengan melakukan penilaian kerusakan pohon. Pohon yang sehat adalah pohon yang dapat mengemban fungsi-fungsi fisiologisnya sesuai dengan potensi genetik yang dimiliki pohon tersebut. Suatu 
pohon dapat dikatakan sakit apabila terdapat patogen-patogen dari keadaan lingkungan tertentu yang mengganggu, sehingga fungsi fisiologisnya tidak berfungsi sebagaimana mestinya karena terjadi penyimpangan dari keadaan normal. Maka dari itu kesehatan pohon harus diperhatikan agar terhindar dari kemerosotan populasi. Selain itu dalam kerangka kesehatan hutan, suatu individu pohon akan tergabung menjadi penyusun populasi hutan sehingga kesehatan pohon merupakan hal yang penting dan harus diperhatikan dalam setiap individu pohon. Salah satu kawasan pelestarian alam yang memiliki banyak persebaran pohon adalah Taman Hutan Raya Wan Abdul Rachman yang termasuk dalam kawasan hutan konservasi. Tahura WAR memiliki luas wilayah 22.249 ha dan terbagi menjadi blok pemanfaatan, blok perlindungan dan blok lainnya [12]. Keanekaragaman biodiversitas pohon yang berada di kawasan Tahura tersebut dapat mengakibatkan terjadinya permasalahan penyakit atau patogen yang menyerang individu individu pohon yang ada. Sehingga perlu adanya suatu tindakan berupa penilaian kesehatan pohon untuk dapat mengidentifikasi penyebab pohon yang terserang penyakit.

Penelitian ini diharapkan dapat memberi manfaat dalam memberikan data dan informasi mengenai tingkat kerusakan pohon yang dinilai melalui aspek lokasi, tipe dan tingkat keparahan kerusakan. Berdasarkan uraian diatas tujuan penelitian ini adalah untuk mengetahui sebaran kondisi kesehatan pohon di hutan konservasi Tahura WAR dengan cara melakukan pemetaan kesehatan pohon menggunakan metode Forest Health Monitoring atau FHM.

\section{Metode Penelitian}

Penelitian ini dilaksanakan pada bulan Mei 2019 dengan lokasi penelitian berada di kawasan Tahura WAR Desa Cilimus, Kecamatan Teluk Pandan, Kabupaten Pesawaran, Provinsi Lampung. Alat yang digunakan pada penelitian ini adalah kamera, phi band, hagahypsometer, teropong, GPS atau Global Position System, software ArcGis 10.1, Ms. Excel, alat tulis, dan buku pengenalan identifikasi kerusakan pohon. Sedangkan bahan yang digunakan meliputi peta kawasan Tahura WAR, tegakan pohon di kawasan hutan konservasi Tahura WAR, tallysheet, patok kayu, tali plastik, plastik dan label nama. Metode yang digunakan dalam penelitian ini adalah metode Forest Health Monitoring dengan pembuatan plot ukur sebanyak 2 klaster plot dengan intensitas sampling sebesar 3\%.

Prosedur penelitian yang dilakukan antara lain pada tahap pertama melakukan pengamatan pohon secara menyeluruh di kawasan Tahura WAR pada klaster plot yang telah dibuat. Tahap kedua melakukan pengukuran pada kondisi kerusakan pohonnya. Menurut [3], melalui metode FHM tanda dan gejala kerusakan dicatat berdasarkan definisi kerusakan tersebut dapat mematikan pohon atau mempengaruhi kemampuan hidup jangka panjang pohon tersebut. Data kerusakan pohon yang digunakan untuk mengetahui indikator kerusakan pohon adalah lokasi, tipe kerusakan, dan nilai ambang batas keparahan. Pengamatan pohon dilakukan pada seluruh bagian mulai dari akar hingga ke daun dan pucuk pohon. Maksimal kerusakan yang dicatat sebanyak tiga kerusakan terparah. Apabila terdapat lokasi kerusakan di tempat yang sama maka yang dipilih adalah yang paling parah kerusakannya. Tahap ketiga melakukan pengambilan titik menggunakan GPS pada setiap individu pohon yang diamati pada klaster plot dan akan diolah datanya menggunakan metode overlay yaitu menumpangtindihkan peta administrasi Tahura WAR dengan data yang diperoleh di lapangan dengan menggunakan metode Software ArcGIS 10.1

Pembuatan peta kerusakan pohon dilakukan dengan melakukan pengambilan titik kordinat sebaran pohon dengan alat GPS. Data titik kordinat tersebut kemudian diolah dari GPS ke komputer dengan menggunakan software DNR Garmin. Kemudian melakukan pengolahan data tahap awal dengan memasukkan data GPS ke laptop dengan menggunakan software Arc. GIS 10.1. Terakhir peta titik kordinat sebaran lokasi pengamatan kesehatan pohon yang diperoleh dioverlay peta dengan kawasan Tahura WAR. Analisis data yang digunakan pada penelitian ini adalah penilaian kerusakan dengan kriteria-kriteria berdasarkan metode FHM. Kondisi kerusakan pohon dihitung berdasarkan nilai indeks kerusakan pohon pada tingkat klaster-plot [6]. Data yang diperoleh dari penilaian kerusakan dihitung nilai indeks kerusakannya dengan kode dan bobot nilai indeks kerusakan (NIK). Menurut Noviady [4], hasil perhitungan akhir dapat diketahui dengan menghitung nilai NIK (kelas sehat, kelas ringan, kelas sedang dan kelas berat) dengan rumus:

$$
N I K=\sum_{i=1}^{n}(x i . y i . z i)
$$

Keterangan $=$ 
NIK = Nilai Indeks Kerusakan pada tingkat pohon

$\mathrm{xi}=$ Nilai bobot pada tipe kerusakan

yi = Nilai bobot pada bagian/lokasi pohon yang mengalami kerusakan

zi = Nilai bobot pada keparahan kerusakan

Kemudian untuk mengetahui kelas kerusakan pohon mengacu pada bobot nilai indeks dengan kriteria berikut

Kelas sehat $=0-<5$

Kelas kerusakan ringan $=6-10$

Kelas kerusakan sedang $=11-15$

Kelas kerusakan berat $=16->21$

Selanjutnya untuk mengetahui kode dan tipe kerusakan, kode dan lokasi kerusakan, kode dan kelas keparahan kerusakan, serta bobot indeks kerusakan dapat diketahui melalui penyajian pada tabel 1, 2, 3 dan 4 . Kode lokasi indeks kerusakan dapat dilihat pada gambar yang tersaji pada gambar 1.

Tabel 1. Kode dan Tipe Kerusakan

\begin{tabular}{llll}
\hline No & Tipe Kerusakan & $\begin{array}{l}\text { Kelas Keparahan } \\
(10 \%-99 \%)\end{array}$ & $\begin{array}{l}\text { Kode Tipe } \\
\text { Kerusakan }\end{array}$ \\
\hline 1 & Kanker & $20 \%$ & 1 \\
2 & Busuk Hati, Tubuh buah (badan buah) & Nihil* & 2 \\
& dan indikator lapuk lanjut & & \\
3 & Luka Terbuka & $20 \%$ & 3 \\
4 & Eksudasi (Resinosis dan gumosis) & $20 \%$ & 4 \\
5 & Batang patah kurang dari 0.91 cm & Nihil* & 11 \\
6 & Malformasi & Nihil* & 12 \\
7 & Akar patah atau mati kurang dari 0.91 cm & $20 \%$ & 13 \\
8 & Hilangnya ujung dominan (mati ujung) & $1 \%$ & 21 \\
9 & Cabang patah atau mati & $20 \%$ & 22 \\
10 & Brum pada cabang atau daerah dalam tajuk & $20 \%$ & 23 \\
11 & Kerusakan daun & $20 \%$ & 24 \\
12 & Daun berubah warna & $30 \%$ & 25 \\
13 & Dan lain-lain & Nihiil & 31 \\
\hline
\end{tabular}

Sumber: USDA Forest Service (2001)

Tabel 2. Kode dan Lokasi Kerusakan

\begin{tabular}{ll}
\hline No & Keterangan \\
\hline 0 & Sehat (tidak ada kerusakan) \\
1 & Akar (terbuka) dan tunggak (dengan tinggi $30 \mathrm{~cm}$ di atas permukaan tanah) \\
2 & Akar dan batang bagian bawah \\
3 & Bagian atas batang (setengah bagian atas dari batang antara tunggak dan dasar tajuk hidup \\
4 & Bagian bawah dan bagian atas batang \\
5 & Bagian atas batang (setengah bagian atas dari batang antara tunggak dari dasar tajuk hidup) \\
6 & Batang tajuk (batng utama di dalam daerah tajuk hidup di atas dasar tajuk hidup) \\
7 & Cabang (lebih besar 2,54 cm pada titik percabnagan terhadap batang utama atau batang tajuk \\
& di dalam daerah tajuk hidup)
\end{tabular}


8 Kuncup dan tunas (pertumbuhan tahun terakhir)

9 Daun

Sumber: USDA Forest Service (2001).

Tabel 3. Kode dan Kelas Keparahan Kerusakan

\begin{tabular}{ll}
\hline Kode & Kelas $(\%)$ \\
\hline 0 & $01-09$ \\
1 & $10-19$ \\
2 & $20-29$ \\
3 & $30-39$ \\
4 & $40-49$ \\
5 & $50-59$ \\
6 & $60-69$ \\
7 & $70-79$ \\
8 & $80-89$ \\
9 & $90-99$
\end{tabular}

Sumber: USDA Forest Service (2001).

Tabel 4. Bobot Indeks Kerusakan Pada Pohon

\begin{tabular}{|c|c|c|c|c|c|c|}
\hline \multirow[t]{2}{*}{ No } & \multicolumn{2}{|c|}{ Tipe Kerusakan } & \multicolumn{2}{|c|}{ Lokasi Kerusakan } & \multicolumn{2}{|c|}{ Keparahan Kerusakan } \\
\hline & Kode & Bobot & Kode & Bobot & Kode & Bobot \\
\hline 1 & 1 & 1,9 & 0 & 1,5 & 0 & \\
\hline 2 & 2 & 1,7 & 1 & 2 & 1 & 1,1 \\
\hline 3 & 3 & 1,5 & 2 & 2 & 2 & 1,2 \\
\hline 4 & 4 & 1,5 & 3 & 1,8 & 3 & 1,3 \\
\hline 5 & 11 & 1,6 & 4 & 1,8 & 4 & 1,4 \\
\hline 6 & 12 & 1,3 & 5 & 1,6 & 5 & 1,5 \\
\hline 7 & 13 & 1 & 6 & 1,2 & 6 & 1,6 \\
\hline 8 & 21 & 1 & 7 & 1 & 7 & 1,7 \\
\hline 9 & 22 & 1 & 8 & 1 & 8 & 1,8 \\
\hline 10 & 23 & 1 & 9 & 1 & 9 & 1,9 \\
\hline 11 & 24 & 1 & & & & \\
\hline 12 & 25 & 1 & & & & \\
\hline
\end{tabular}

Sumber : USDA Forest Service 2001 

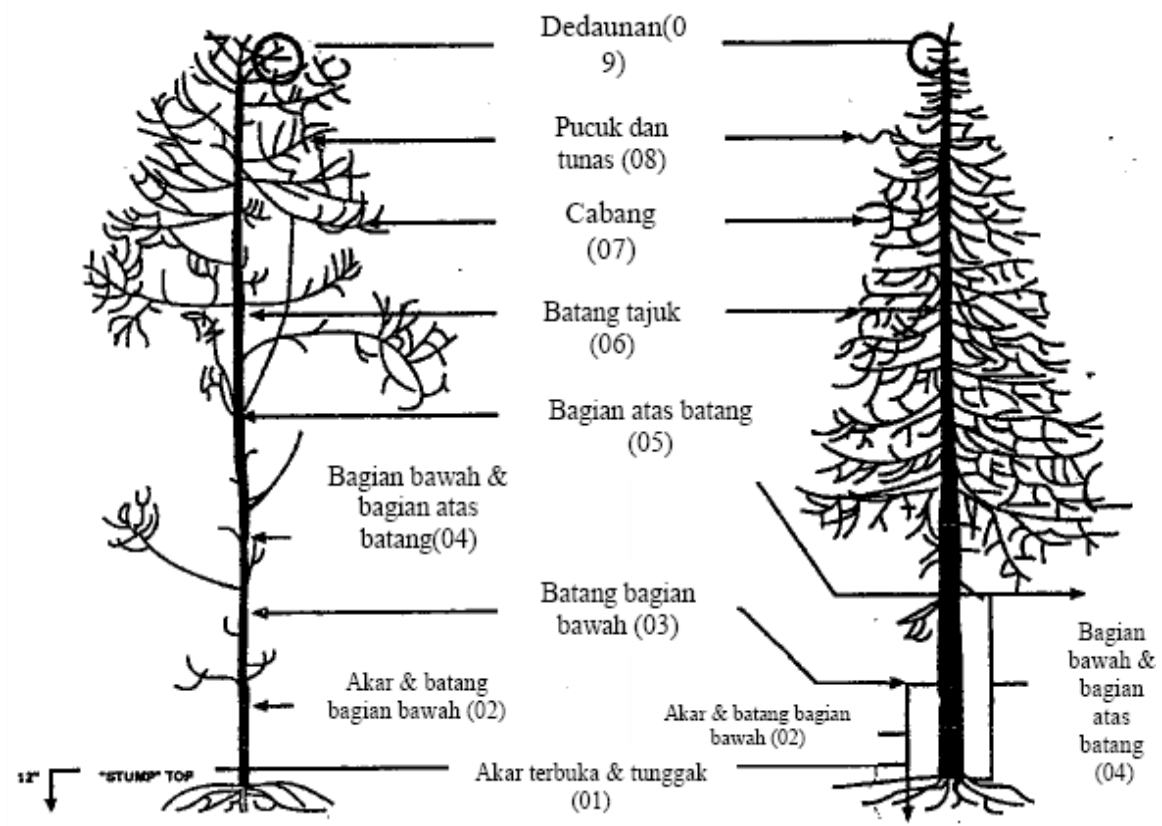

Gambar 1.Kode Lokasi untuk Indikator Kerusakan (USDA Forest Service, 2001)

\section{Hasil dan Pembahasan}

\subsection{Inventarisasi Pohon di Kawasan Hutan Konservasi Tahura WAR}

Berdasarkan hasil penelitian yang dilakukan di kawasan Taman Hutan Raya Wan Abdul Rachman, diperoleh total 8 jenis pohon dari total 47 individu pohon yang terdapat dalam klaster plot yang dibuat yaitu terdiri dari 29 individu pohon pada klaster plot 1 dan 18 individu pohon pada klaster plot 2. Inventarisasi menggunakan intensitas sanpling (IS) sebesar 3\% dan pengukuran dilakukan pada tingkat jenis pohon. Hasil perhitungan jumlah pohon pada dua klaster plot di kawasan hutan konservasi Tahura WAR tersaji pada tabel 5.

Tabel 5. Inventarisasi jenis pohon di kawasan Hutan Konservasi Tahura WAR

\begin{tabular}{llll}
\hline No & Jenis Pohon & Nama Latin & Jumlah \\
\hline 1 & Jengkol & Achidendron pauciflorum & 7 \\
2 & Durian & Durio zibhetinus & 22 \\
3 & Petai & Parkia speciosa & 12 \\
4 & Rambutan & Naphelium lappaceum & 2 \\
5 & Waru & Hibiscus tiliaceus & 1 \\
6 & Kemiri & Aleurites moluccanus & 1 \\
7 & Melinjo & Gnetum gnemon & 1 \\
8 & Sengon Buto & Enterolobium cylocarpum & 1 \\
\hline Jumlah & & & 47 \\
\hline
\end{tabular}

Jenis pohon yang mendominasi pada kawasan konservasi di desa Cilimus, Teluk Pandan yaitu pohon Durian (Durio zibethinus) dengan jumlah 22 pohon sedangkan jenis pohon yang paling sedikit jumlahnya di kawasan tersebut adalah pohon waru (Hibiscus tiliaceus), pohon kemiri (Aleurites moluccanus), pohon melinjo (Gnetum gnemon) dan pohon sengon buto (Enterolobium cylocarpum) dengan jumlah yang sama sebanyak 1 pohon. Menurut [9] bahwa jamur, bakteri, dan patogen atau penyakit sebenarnya dibutuhkan dalam suatu hutan agar dapat ditentukan struktur fungsi 
ekosistem hutan tersebut. Namun apabila jumlahnya melebihi ambang batas yang diperbolehkan maka tentunya akan membahayakan lingkungan sekitar ekosistem hutan tersebut dan dapat menyebabkan hutan tersebut tidak sehat hingga hutan menjadi tidak lestari. Menurut [8], kerusakan suatu pohon akan berpengaruh pada fungsi fisiologis pohon namun bergantung pada lokasi, jenis dan tingkat keparahannya. Kerusakan pohon yang melewati ambang batas kerusakan akan menurunkan laju pertumbuhan pohon dan dapat pula menyebabkan kematian pohon.

\subsection{Kesehatan Pohon}

Jumlah tegakan pohon yang diteliti pada kawasan hutan konservasi Tahura WAR adalah sebanyak 47 tegakan. 4 tegakan pohon tidak mengalami kerusakan dan berada pada kategori baik, 16 pohon termasuk dalam kategori sedang dan 27 pohon berada pada kategori buruk. Kondisi tegakan pohon tersaji pada tabel 6 dan peta kesehatan pohon pada kedua klaster plot tersaji pada gambar 2 dan 3.

Tabel 6. Kelas Kerusakan Pohon di Kawasan Hutan Konservasi Tahura WAR

\begin{tabular}{llll}
\hline No & Kriteria & Jumlah & Persentase \\
\hline 1 & Sehat & 4 & $9 \%$ \\
2 & Sedang & 16 & $34 \%$ \\
3 & Buruk & 27 & $57 \%$ \\
\hline Jumlah & & 47 & $100 \%$ \\
\hline
\end{tabular}

Kerusakan kerusakan pohon yang terjadi dapat memberikan gangguan terhadap fungsi hutan yang selama ini diemban. Ada banyak dampak yang ditimbulkan dari suatu kerusakan pohon yaitu menurunnya produktivitas pohon tersebut, nilai kondisi tajuk akan rendah dan lambat laun mengalami kematian serta berdampak pada kesehatan hutan secara keseluruhan. Menurut [9], saat ini banyak kegiatan pengelolaan hutan oleh manusia yang menimbulkan berbagai gangguan. Gangguan-gangguan tersebut lah yang bisa saja dapat menimbulkan kerusakan-kerusakan pada pohon. Menurut [7], dampak dari kerusakan-kerusakan pohon yang ada akan mengakibatkan tingkat pertumbuhan yang menurun, kondisi tajuk yang rendah, kehilangan biomassa dan terutama akan menyebabkan kematian.

Berdasarkan hasil pengamatan dengan menggunakan metode FHM, diperoleh hasil penelitian bahwa kondisi kerusakan pohon di area hutan konservasi tersebut tergolong kelas sehat dengan NIK sebesar 9\%, dalam kategori sedang persentasenya sebesar 34\% dan kategori buruk persentasenya 57\%. Pohon dikategorikan dalam kondisi yang sehat apabila mengalami kerusakan sebesar 0-5, kriteria sedang apabila nilai pada NIK 11-15 dan kriteria berat atau buruk apabila nilai NIK 16-21. Kerusakan-kerusakan pohon yang terjadi pada kawasan hutan konservasi di Desa Cilimus Kecamatan Teluk pandan tersebut disebabkan oleh berbagai macam faktor gangguan seperti hama atau serangga, penyakit atau patogen, jamur, bakteri yang melebihi ambang batas keparahan serta berbagai aktivitas yang dilakukan manusia di dalam hutan seperti pemadatan tanah, gangguan manusia terhadap pohon, dan kesalahan dalam penempatan pohon [1]. 


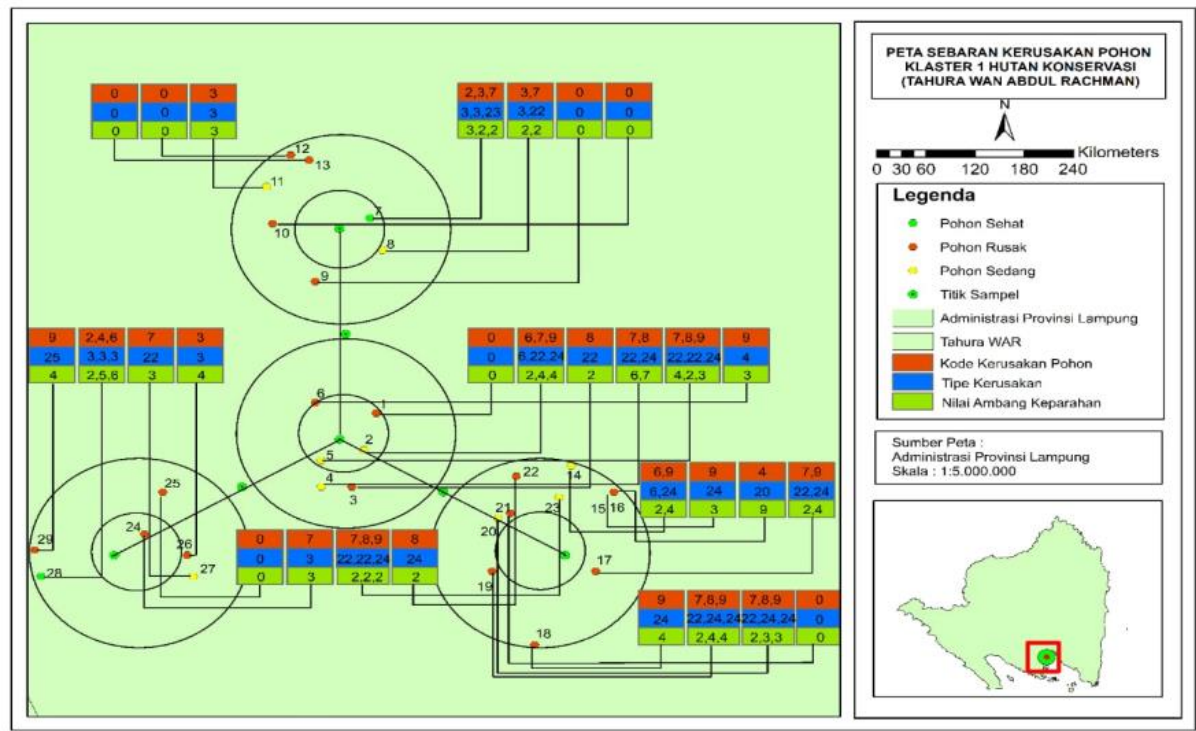

Gambar 2. Peta Sebaran Kesehatan Pohon Klaster-Plot 1 di Tahura WAR

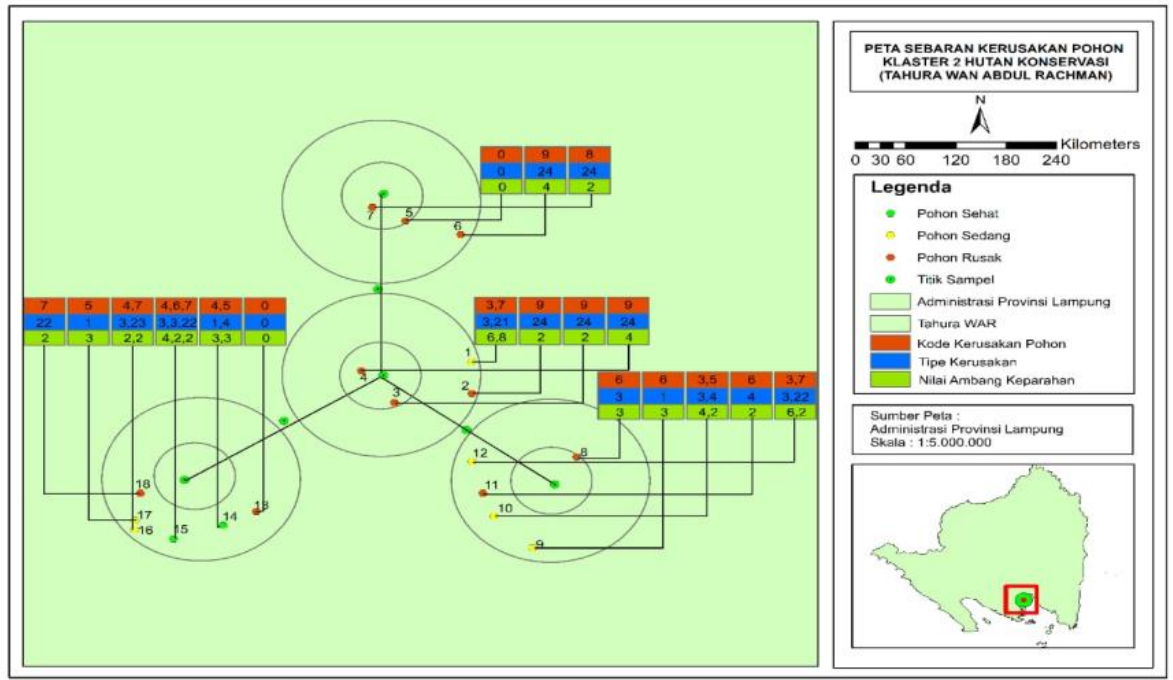

Gambar 3. Peta Sebaran Kesehatan Pohon Klaster Plot 2 Tahura WAR

\subsection{Tipe Kerusakan Pohon}

Berdasarkan hasil pengamatan kondisi kesehatan pohon di kawasan hutan konservasi tersebut diperoleh 10 tipe penyakit dari total 15 penyakit. Tipe-tipe kerusakan pohon dikawasan hutan konservasi yang berhasil diidentifikasi tersaji pada tabel 7.

Tabel 7. Tipe Kerusakan Pohon di Hutan Konservasi Tahura WAR

\begin{tabular}{llll}
\hline No & Tipe Kerusakan & Jumlah & Persentase \\
\hline 1 & Kanker & 3 & $4,76 \%$ \\
2 & Luka terbuka & 16 & $25,40 \%$ \\
3 & Resinosis/gumoisis & 3 & $4,76 \%$ \\
4 & Batang pecah & 0 & $0,00 \%$ \\
5 & Sarang rayap & 2 & $3,17 \%$
\end{tabular}




\begin{tabular}{llll}
6 & Batang/akar patah <3 kaki dari batang & 0 & $0,00 \%$ \\
7 & Brum pada akar/batang & 0 & $0,00 \%$ \\
8 & Akar patah/mati <3 kaki dari batang & 0 & $0,00 \%$ \\
& & 1 & \\
9 & Liana & & $1,59 \%$ \\
10 & Hilangnya pucuk dominan, mati pucuk & 1 & $1,59 \%$ \\
11 & Cabang patah/mati & 14 & $22,22 \%$ \\
12 & Percabangan atau brum yang berlebihan & 2 & $3,17 \%$ \\
13 & Daun, pucuk atau tunas rusak & 20 & $31,75 \%$ \\
14 & Daun berubah warna (tidak hijau) & 1 & $1,59 \%$ \\
15 & Karat puru & 0 & $0,00 \%$ \\
\hline
\end{tabular}

Berdasarkan tabel 7, diketahui bahwa tipe kerusakan yang paling dominan adalah nomor 2 yaitu luka terbuka dengan persentase sebesar $25,40 \%$. Luka terbuka tersebut kemungkinan banyak disebabkan oleh gangguan dari aktivitas manusia namun bisa juga disebabkan oleh interaksi faktor botik dan abiotik dalam ekosistem hutan. Menurut [10], Luka terbuka merupakan suatu luka yang ditandai dengan mengelupasnya kulit kayu atau kayu bagian dalam telah terbuka dan tidak ada lapuk lanjut. Luka pangkasan yang memotong ke dalam kayu batang utama dikodekan sebagai luka terbuka jika memenuhi nilai ambang, namun jika luka tidak mengganggu keutuhan kayu batang utama maka tidak termasuk.

Setiap pohon yang sudah mengalami kerusakan memiliki letak lokasi yang berbeda satu sama lain tergantung di bagian mana lokasi kerusakan itu dijumpai saat dilakukan pengambilan data secara langsung di lapangan. Kondisi kerusakan pohon diukur berdasarkan lokasi ditemukannya kerusakan, yaitu pada: akar, batang, cabang, tajuk, daun, pucuk, dan tunas dalam metode FHM [11]. Lokasi kerusakan pohon tersaji pada tabel 8.

Tabel 8. Persentase lokasi kerusakan pohon di kawasan hutan konservasi Tahura WAR

\begin{tabular}{llll}
\hline Kode & Lokasi Kerusakan & Jumlah & Persentase (\%) \\
\hline 1 & Akar dan tunggak & 0 & $0,00 \%$ \\
2 & Akar dan batang bagian bawah & 2 & $3,17 \%$ \\
3 & Batang bagian bawah & 7 & $11,11 \%$ \\
4 & Bagian bawah dan bagian atas batang & 5 & $7,94 \%$ \\
5 & Bagian atas batang & 3 & $4,76 \%$ \\
6 & Batang tajuk & 7 & $11,11 \%$ \\
7 & Cabang & 16 & $25,40 \%$ \\
8 & Pucuk dan tunas & 8 & $12,70 \%$ \\
9 & Daun & 15 & $23,81 \%$ \\
\hline
\end{tabular}

Berdasarkan tabel 8, diketahui bahwa bagian pohon yang dominan mengalami kerusakan adalah di bagian cabang pohon dengan kode 7 dan persentase sebesar 25,40\% sedangkan yang paling sedikit mengalami kerusakan adalah bagian akar dan tunggak dengan kode 1 dan persentase sebesar $0 \%$ serta pada akar dan bagian batang bawah yang memiliki persentase sebesar $3,17 \%$.

\section{Kesimpulan}

Kesehatan pohon di kawasan hutan konservasi Tahura WAR secara umum berada pada kondisi buruk dengan intensitas sebanyak 47 tegakan pohon. Sebanyak 4 tegakan dalam kondisi sehat, 16 tegakan dalam kondisi sedang dan 
27 tegakan pohon berada pada kondisi buruk. Tipe kerusakan pohon pada kawasan hutan konservasi Tahura WAR adalah sebanyak 10 tipe kerusakan diantaranya meliputi kanker (3 pohon), luka terbuka (16 pohon), resinosis (3 pohon), sarang rayap (2 pohon), liana (1 pohon), hilangnya pucuk dominan (1 pohon), cabang patah (14 pohon), percabangan/brum berlebih ( 2 pohon), daun/pucuk rusak (20 pohon), dan daun berubah warna (1 pohon). Kerusakan yang dialami oleh beberapa bagian pohon terdapat pada bagian akar dan batang bagian bawah (2 pohon), batang bagian bawah ( 7 pohon), bagian bawah dan atas batang ( 5 pohon), bagian atas batang ( 3 pohon), batang tajuk (7 pohon), Cabang (16 pohon), pucuk/tunas (8 pohon ) dan daun (15 pohon).

\section{Referensi}

[1] Barus, Agung M. (2017) “Pemetaan Kesehatan Pohon di Kawasan Arboretum Universitas Sumatera Utara”, dalam Skripsi Universitas Sumatera Utara, Medan

[2] Irwanto (2006) “Penilaian Kesehatan Hutan Tegakan Jati (Tectona grandis) dan Eucalyptus (Eucalyptus pellita) pada kawasan hutan Wanagama I", Universitas Gadjah Mada, Yogyakarta

[3] Mangold, R. (1997) “Forest Health Monitoring: Field MethodsGuide”, United States Departement of Agriculture Forest Service, Washington

[4] Noviady, Reza Ramdan Rivai (2015) "Identifikasi kondisi kesehatan pohon peneduh di kawasan ecopark, cibinong science centerbotanicgardens", Jurnal Masyarakat Biodiv Indonesia 1 (6), Bogor

[5] Nuhamara, S.T., Kasno, Irawan, U.S. (2001) “Assessment on Damage Indicators in Forest Health Monitoring to Monitor the Sustainability of Indonesian Tropical Rain Forest", dalam Forest Health Monitoring to Monitor The Sustainability of Indonesian Tropical Rain Forest, Volume II, Japan: ITTO dan Bogor: SEAMEO BIOTROP

[6] Nuhamara, S.T. dan Kasno (2001) "Present Status of Crown Indicators in Forest Health Monitoring to Monitor the Sustainability of Indonesian Tropical Rain Forest", dalam Forest Health Monitoring to Monitor The Sustainability of Indonesian Tropical Rain Forest, Volume I. Japan: ITTO dan Bogor: SEAMEO BIOTROP

[7] Permadi P, Lelana NE, Anggraeni I, Darwiati W (2017) "Rumusan Seminar didalam Seminar Nasional Kesehatan Hutan dan Kesehatan Pengusahaan Hutan untuk Produktivitas Hutan", Bogor, Pusat Litbang Peningkatan Produksi Hutan

[8] Putra E. I. (2004) "Pengembangan Metode Penilaian Kesehatan Hutan Alam Produksi”, dalam Tesis Institut Pertanian Bogor, Bogor

[9] Safe'i R. (2015) “Kajian Kesehatan Hutan dalam Pengelolaan Hutan Rakyat di Provinsi Lampung”, dalam disertasi, Bogor Institut Pertanian Bogor

[10] Safe'i R, Machya Kartika T. (2016) "Kesehatan Hutan: Penilaian Kesehatan Hutan Menggunakan Teknik Forest Health Monitoring", Yogyakarta, Plantaxia

[11] Sitinjak, E.V, Duryat dan Santoso, T. (2016) “Status Kesehatan Pohon Pada Jalur Hijau dan Halaman Parkir Universitas Lampung”, Jurnal Sylva Lestari 4 (2): 101-108.

[12] Unit Pelaksana Terpadu Daerah Taman Hutan Raya Wan Abdul Rachman tahun (2016) "Buku Informasi Tahura", Bandarlampung

[13] USDA Forest Service (2001) "Forest Health Monitoring to Monitor the Sustainability of IndonesianTropical Raint forest", SEAMEO BIOTROP, Indonesia 